\title{
SOLAR SPECTRAL INFLUENCE ON THE PERFORMANCE OF CRYSTALLINE BASED PHOTOVOLTAIC MODULES UNDER HOT WEATHER CONDITIONS
}

\author{
Indra Bahadur Karki* and David Faiman** \\ *Department of Physics, Patan Multiple Campus, Patan-Dhoka, Tribhuvan University, Nepal. \\ **Department of Solar Energy \& Environmental Physics, Sede-Boquer Campus, Ben-Gurion University, Israel.
}

\begin{abstract}
The purpose of this paper is to analyze the effects of solar sky spectrum and module temperature of the amophous and crystalline-based photovoltaic (PV) modules. In this study, we analyzed the effects of changing spectrum after noontime to till sunset on the three most common types of PV modules - polycrystalline silicon (p$\mathrm{Si})$, single crystal silicon (c-Si), and amorphous silicon (a-Si). Short circuit current $\left(\mathrm{I}_{\mathrm{sc}}\right)$, open circuit voltage $\left(\mathrm{V}_{\mathrm{oc}}\right)$, fill factor (FF) and maximum power output $\left(\mathrm{P}_{\text {max }}\right.$ ) of each modules were adjusted to standered test conditions (STC) using corresponding temperature coefficient parameters. This paper describes straightforward methods for directly measuring the influences of variations in solar spectral irradiance as a function of time-of-day. We observed, the spectral sensitivity functions (SSFs) for the current and power, increases with increase in pressure corrected airmass (AM) for amorphous, mono and poly crystalline silicon modules. In the case of amorphous modules, it seems to be opposite. This means that PV modules are mostly influenced by the sky spectrum and module temperature.
\end{abstract}

Keywords: Module temperature; Sky Spectrum; PV modules; Spectral Response; Spectral Sensitivity functions.

\section{INTRODUCTION}

The spectral sensitivity of solar cell is wavelength dependence of it's' short-circuit current per unit energy of the incident optical radiation $[1,2]$. In photovoltaic technology, the electric current generated by photovoltaic devices is influenced by the spectral distribution (spectrum) of sunlight $[3,4,5]$. It is also commonly understood that the spectral distribution of sunlight varies during the day, being "redder" at sunrise and sunset, and "bluer" at noon. The magnitude of the influence that the changing spectrum has on performance can vary significantly, depending on the photovoltaic technology being considered [6]. In any case, spectral variation introduces a systematic influence on performance that is time-of-day dependent. The influence of spectral variations on photovoltaic devices has been documented by several authors $[7,8,9,10,11]$.

In this study, we analyzed the effects of changing spectrum after noon time to till sunset on the three most common types of PVs - polycrystalline silicon (p-Si), single crystal silicon (c-Si), and amorphous silicon (a-Si). Each panel's current, voltage, fill factor and maximum power output were adjusted to STC using corresponding temperature coefficient parameters. The crystalline and amorphous panels were expected to have different responses at STC. It was anticipated that the crystalline panels would produce higher outputs when the spectrum had a larger portion of the total irradiance coming from the red wavelengths, the amorphous producing more power when blue light was stronger. This corresponded to the standardized yields being greater in the late after noon for the crystalline panels and at after noon time for the amorphous.

This paper describes straightforward methods for directly measuring the influences of variations in solar spectral irradiance as a function of time-of-day. The empirical relationships that result can be directly applied during outdoor performance testing of modules $[4,7,10]$.

Author for Correspondence: Indra Bahadur Karki Department of Physics, Patan Multiple Campus, Tribhuvan University, Nepal. E-mail: indrakarky@gmail.com. 


\section{EXPERIMENTAL}

\section{System Description \& Set-Up}

The experiment was carried out at Ben-Gurion National Solar Energy Center,Sede-Boqer, Israel, which is located in the Negev desert (Lat.: $30.8^{\circ} \mathrm{N}$, Lon.: $34.8^{\circ} \mathrm{E}$, Alt.: $475 \mathrm{~m})$.

The three most common types of modules, a-Si, poly-Si and mono-Si were placed on a movable stand. The two pyranometers (PSP and LiCor) were placed in the same plane of the modules and thermocouples were taped to their rare surfaces. The I-V curves were measured for all modules, using a Daystar I-V curve tracer. The measured temperature coefficient parameters $\left(\alpha_{\mathrm{sc}}, \alpha_{\mathrm{pp}}, \beta_{\mathrm{oc}}, \beta_{\mathrm{pp}}, \gamma_{\mathrm{pp}}\right.$, and $\left.\delta_{\mathrm{FF}}\right)$ of three types of modules are given Table 1 [12].

Table 1:
Experiments

The spectral sensitivity experiments started after solar noon IST 1:30PM.The measurements were conducted in clear skies day and every one hour till 4:00PM and then 3 measurements were conducted in each half an hour till sun set. The experiments were continuing until sunset.

\section{RESULTS AND DISCUSSION}

Solar module parameters like $\mathrm{I}_{\mathrm{sc}}, \mathrm{I}_{\mathrm{pp}}, \mathrm{V}_{\mathrm{oc}}, \mathrm{FF}$ and $\mathrm{P}_{\text {max }}$ were found from each I-V curve drawn at different temperatures and were plotted them against the temperature and there by found the temperature coefficients of each parameter using regression equation.

\begin{tabular}{|c|c|c|c|c|c|c|c|c|}
\hline Brand & Model & Type & $\alpha_{s c}(m A / K)$ & $\alpha_{p p}(m A / K)$ & $\beta_{o c}(m V / K)$ & $\beta_{p p}(m V / K)$ & $V_{p p}(m W / K)$ & ${ }_{\mathrm{FF}}((\% / \mathrm{K})$ \\
\hline Solarex & SX45 & $\mathrm{p}-\mathrm{Si}$ & +1.63 & +0.44 & -73.9 & -80.0 & -201 & -0.133 \\
\hline Siemens & SM55 & $\mathrm{c}-\mathrm{Si}$ & +1.2 & -0.3 & -67.1 & -68.4 & -201 & -0.105 \\
\hline Sovluxa & - & $\mathrm{Si}$ & +5.9 & +7.6 & -21.8 & -13.7 & -34.3 & +0.057 \\
\hline Unisolar & US32 & $\mathrm{a}-\mathrm{Si}$ & +2.8 & +3.3 & -77.4 & -39 & -20.5 & +0.088 \\
\hline
\end{tabular}

\section{Description of Measurement Procedure}

During the test to measure the spectral sensitivity of three module types: Siemens SM55 (single crystal Si), Solarex SX-45 (polycrystalline Si), single junction Sovlux and multi junction Unisolar US32 (amorphous $\mathrm{Si}$ ) in the following manner. The modules were placed on a movable stand that permitted us to study them at normal incidence of the direct beam component of the radiation. A thermopile pyranometer (Eppley PSP) and Li-Cor (serial\# 6456) were placed in the common plane of the modules. The thermocouples were taped in the center of the back of the module because this is most- representative of the temperature. The data logger (Campbell 21X Micrologger S/N 10278) recorded the pyranometers data and temperature of modules. Approximately each half an hour, from after noon time to sun set, the module plane was set at normal incidence and I-V curves were measured for those modules, using a Daystar I-V curve tracer. Calibration of the pyranometer was checked, using the normal incidence method [5] relative to a calibrated reference instrument maintained solely for such purposes. A Solarex SX-45 module is a reference module that is normally kept indoors except for occasions such as this was used as a control module. All $\mathrm{I}-\mathrm{V}$ curves were adjusted to a standard insolation level of $1000 \mathrm{~W} \mathrm{~m}^{-2}$ and a module temperature of $25^{\circ} \mathrm{C}$ using measured temperature coefficient parameters.
The outdoor photovoltaic characterization of the three type (single, polycrystalline and amorphous) of PV modules on clear sky day were performed. All I-V curve parameters (Isc, $I_{p p}, V_{o c}, V_{p p}, P_{\text {max }}, F F$ ) of the three type ( single, polycrystalline and amorphous) of PV modules were adjusted to $1000 \mathrm{Wm}^{-2}$ total irradiance and $25{ }^{\circ} \mathrm{C}$ module temperature. All I-V curve parameters

at STC corrected as a function of absolute air mass (pressure correction) were plotted at different types of PV modules (monocrystalline Siemenes SM55, poly crystalline Solrex SX45 and amorphous panels Sovlux and Unisolar).

These curves have been normalized to their respective AM1.5 in order to enable quantitative comparisons to be made the various module types, each of which has a different I-V curve parameters value at STC. We observed, the SSFs for the current and power, increases with increase pressure corrected AM, (Fig,1-8) for poly crystalline silicon modules, and in the case of amorphous panels, it seems to be opposite. This means that PV modules are effected by the sky spectrum. 
$\operatorname{Voc}(\mathbf{S T C})$ vs $\mathrm{AMa}(\mathbf{S X} 45)$

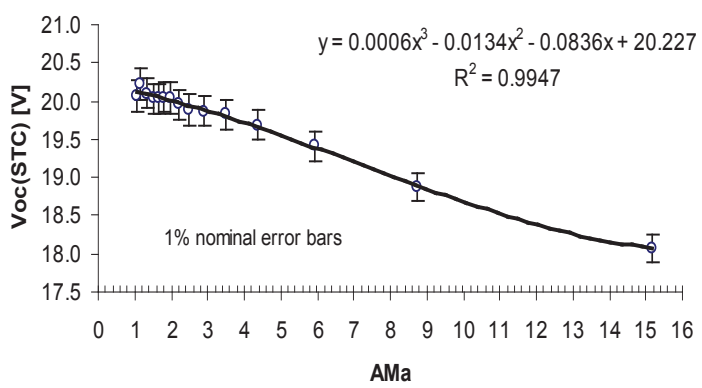

$\operatorname{Pmax}(\mathrm{STC})$ vs AMa

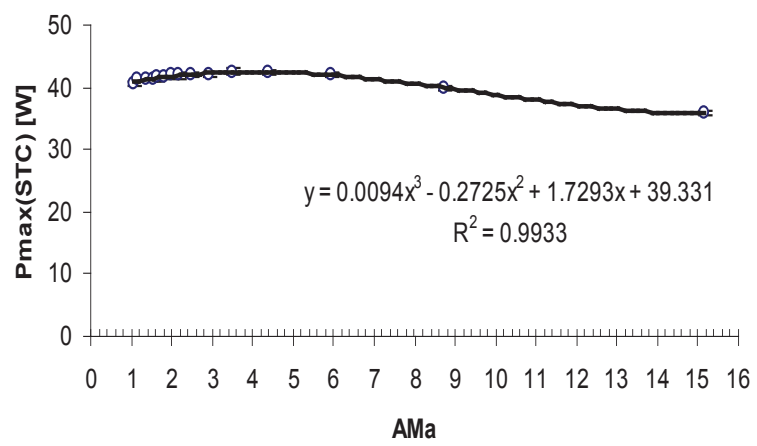

Isc(STC) vs AMa(SX45)

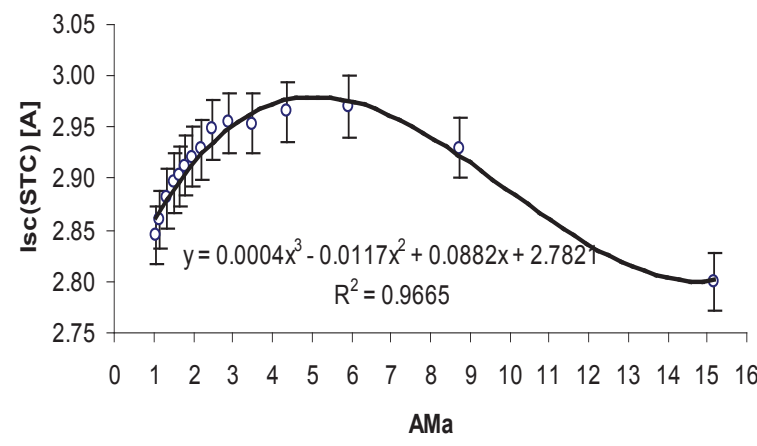

FF(STC) vs AMa(SX45)

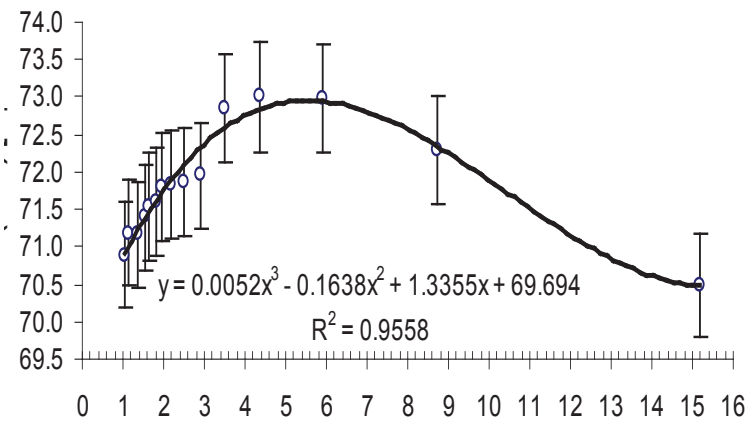

AMa

Fig 1-4. Graphs on the I-V curve parameters at STC corrected as a function of absolute air mass (pressure correction) at different types of PV modules.

Isc Spectral Sensitivity Factor vs AMa(Unisolar)

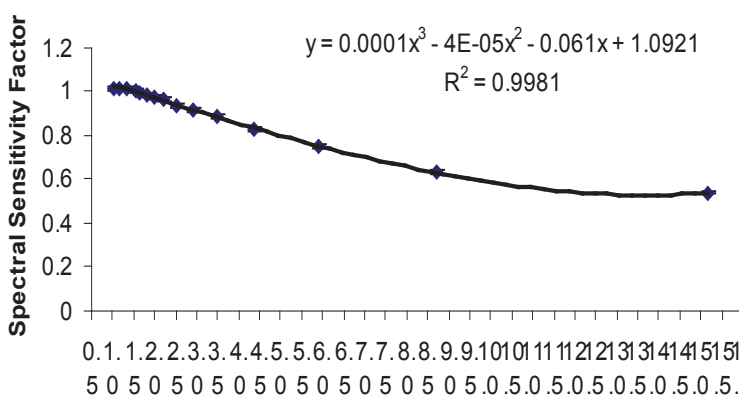

$\mathrm{AMa}$

Isc SS Factor vs AMa-SX45

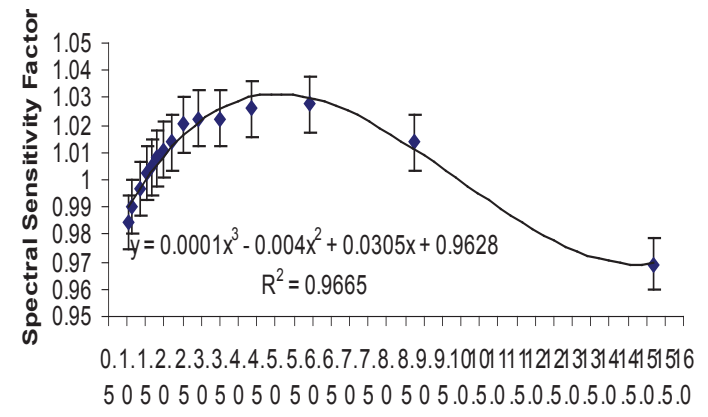

$\mathrm{AMa}$
Power SS Factor vs AMa(Unisolar)

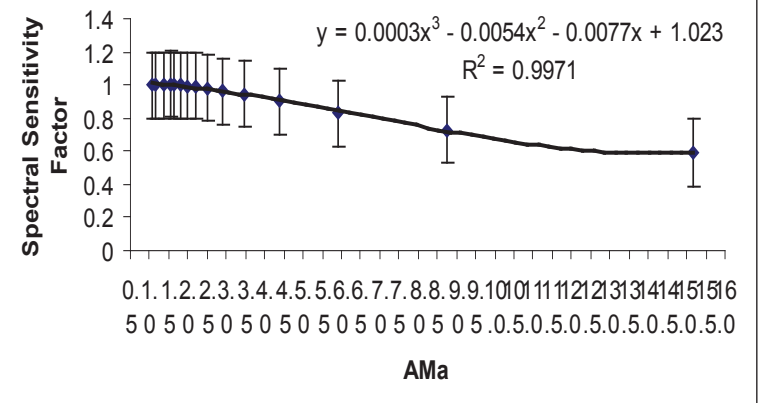

Power SS Factor vs AMa(SX45)

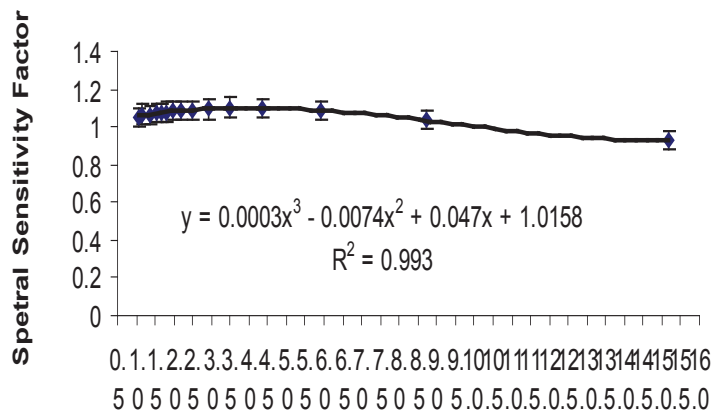

AMa

Fig.5-8. Spectral Sensitivity Factor vs. absolute air mass (pressure correction) at different types of PV modules. 


\section{Measurement results}

Solar module parameters like $I_{s c}, I_{p p}, V_{o c}, V_{p p}, F F$, and $\mathrm{P}_{\max }$ were found from each $\mathrm{I}-\mathrm{V}$ curve drawn at different temperatures and were plotted them against the temperature and thereby found the temperature coefficients of each parameter using regression equation.

The temperature coefficients parameters of various Solar PV modules were measured from graphs, given as follows [12].

\section{Monocrystalline (SM55):}

$$
\begin{array}{ll}
\frac{d V_{o c}}{d T}=-69.0 \mathrm{mV} / \mathrm{K} & \frac{d V_{P P}}{d T}=-67.6 \mathrm{mV} / \mathrm{K} \\
\frac{d I_{P P}}{d T}=-0.8 \mathrm{~mA} / \mathrm{K} & \frac{d I_{s c}}{d T}=1.3 \mathrm{~mA} / \mathrm{K} \\
\frac{d F}{d T}=-0.107 \% / \mathrm{K} & \frac{d P_{\text {Max }}}{d T}=-208 \mathrm{~mW} / \mathrm{K}
\end{array}
$$

\section{Polycrystalline (SX-45):}

$$
\begin{array}{cc}
\frac{d V_{o c}}{d T}=-73.9 m \mathrm{~m} / K & \frac{d V_{P P}}{d T}=-80.0 \mathrm{mV} / \mathrm{K} \\
\frac{d I_{S C}}{d T}=+1.6 \mathrm{~mA} / \mathrm{K} & \frac{d I_{P P}}{d T}=+0.4 \mathrm{~mA} / \mathrm{K} \\
\frac{d P_{\max }}{d T}=-201 \mathrm{~mW} / \mathrm{K} & \frac{d F}{d T}=-0.133 \% / K
\end{array}
$$

\section{Amorphous (Sovlux):}

The results show that $V_{o c}, V_{p p}, F F$, and $P_{\max }$ decreases with

$$
\begin{array}{ll}
\frac{d V_{o c}}{d T}=-23.2 \mathrm{mV} / \mathrm{K} & \frac{d V_{P P}}{d T}=-15.7 \mathrm{mV} / \mathrm{K} \\
\frac{d I_{S C}}{d T}=+6.5 \mathrm{~mA} / \mathrm{K} & \frac{d I_{P P}}{d T}=+10.5 \mathrm{~mA} / \mathrm{K} \\
\frac{d P_{\max }}{d T}=-29.4 \mathrm{~mW} / \mathrm{K} & \frac{d F}{d T}=+0.075 \% / K
\end{array}
$$

increase in temperature in mono and poly crystalline panels. In a-Si (SOVLUX), fill factor FF increases with increase in temperature. The open circuit voltage is strongly dependent on module temperature and current not.

\section{CONCLUSION}

Outdoor performances of a-Si, p-Si, and c-Si PV modules have been investigated at outdoor hot weather conditions. The effects of solar sky spectrum and module temperature of the amorphous and crystalline- based PV modules were analyzed. The SSFs for the current and power, increases with increase in pressure corrected airmass for amorphous, mono and poly crystalline silicon modules. In the case of amorphous modules, it seems to be opposite. The results indicated that crystalline PV modules are highly influenced by the sky spectrum and cell temperature in the clear skies day.

\section{ACKNOWLEDGEMENT}

I.B. Karki would like to thank the Bonna Terra Foundation, the Albert Katz International School for Desert Studies, Israel and Tribhuvan University, Kathmandu, Nepal for financial and technical support.

\section{REFERENCES}

[1] Martin, A.G. 1982. Solar Cells, Operating Principles, Technology, and Applications, Prentice-Hall, Inc., Englewood Cliffs, N.J. 07632.

[2] Corkish, R.P. 2004. Solar Cells' in Cutler J. Cleveland (ed.), Encyclopedia of Energy. Volume 5, Elsevier Inc., California. pp:545 - 557 .

[3] Chegaar, M. and Mialhe P. 2008. Effect of atmospheric parameters on the silicon solar cells performance. Journal of Electron Devices. 6: 173-176.

[4] King, D. L., Kratochvil J. A., and Boyson W. E. 1997. Measuring Solar Spectral and Angle-of-Incidence Effects on Photovoltaic Modules and Solar Irradiance Sensors, Presented at the $26^{\text {th }}$ IEEE PVSC, Anaheim,California.

[5] Feltrin, A. and Freundlich A. 2008. Material considerations for terawatt level deployment of photovoltaics, Renewable Energy. 33 (2) : 180-185.

[6] Thevenard, D., Driesse, A., Turcotte, D., and Poissant, Y. 2010. Uncertainty in Long-Term Photovoltaic Yield Predictions. Technical Report. 2010-122. (RP-TEC) .411-IEARES.Canmet ENERGY, Natural Resources, Canada.

[7] Berman, D., Faiman, D., and Farhi, B. 1999. Sinusoidal spectral correction for high precision outdoor module characterization. Solar Energy Materials \& Solar Cells. 58: 253-264.

[8] Hirata, Y. and Tani, T. 1995. Output Variation of PV Modules with Environmental Factors. Solar Energy. 55: 463-468.

[9] King, D.L., Eckert P.E. 1996. Characterizing (Rating) theperformance of large photovoltaic arrays for all operating conditions. 25 $5^{\text {th }}$ IEEE PV Specialists Conference, Washington DC, USA, IEEE, Piscataway, NJ., USA. pp: 1385-1388.

[10] King, D.L. 1996. Photovoltaic Module and Array Performance Characterization Methods for All System Operating Conditions. NREL/SNL Program Review, AIP Press. pp:347-368.

[11] Fthenakis, V. 2009. Sustainability of Photovoltaics: The case for thin-film solar cells, Renewable and Sustainable Energy Reviews. 13 ( 9): 2746-2750.

[12] Karki, I.B. 2003. AC-Module Type DC-AC Inverters for Grid Connected Photovoltaic (PV) Systems: A Study of Their Performance Dependence on External Conditions. M.Sc. Thesis. Department of Solar Energy \& Environmental Physics, Ben-Gurion University, Sede-Boqer, Israel. 